\title{
Juventude feminina do meio rural: sentidos sobre educação e perspectivas sobre futuro
}

\author{
Adolfo Pizzinato \\ Pontifícia Universidade Católica do Rio Grande do Sul - Porto Alegre - RS - Brasil \\ Milene Mabilde Petracco \\ Instituto Federal Sul-Rio-Grandense - Charqueadas - RS - Brasil \\ Cristiano Hamann \\ Universidade Federal do Rio Grande do Sul - Porto Alegre - RS - Brasil \\ João Pedro Cé \\ Pontifícia Universidade Católica do Rio Grande do Sul - Porto Alegre - RS - Brasil \\ Eduarda Noal Rosa \\ Pontifícia Universidade Católica do Rio Grande do Sul - Porto Alegre - RS - Brasil
}

\section{Resumo}

Este artigo tem como objetivo promover reflexões a respeito da educação e das perspectivas de futuro de jovens mulheres do meio rural residentes em diferentes municípios do interior do Rio Grande do Sul, Brasil. Foram realizadas entrevistas e composições fotográficas, ambas entendidas como produções narrativas, com quarenta e oito jovens. Seguindo um processo analítico embasado nos pressupostos da Teoria Fundamentada, sete entrevistas foram selecionadas e estudadas em profundidade, tendo em vista dois aspectos: serem representativas das mesoregiões do estado e indicarem conteúdos transversais: trajetória educacional, projetos de vida, profissão e futuro. Este estudo aponta que a escola desempenha uma função para além da aprendizagem formal, consistindo em um espaço de lazer e convivência, de construção de identificações e também de projeção para o futuro para além do campo profissional, entretanto, também evidencia a falta de um trabalho de orientação particularizado a essas juventudes.

Palavras-chave: Jovens; projeto vital; população rural.

\section{Women youth from countryside areas: directions on education and perspectives on the future}

\begin{abstract}
This article aims to promote reflections about the education and future perspectives of young rural women living in different cities in the countryside of Rio Grande do Sul, Brazil. Interviews and photographic compositions were carried out, both understood as narrative productions, with forty eight young people. Following an analytical process based on the assumptions of Grounded Theory, seven interviews were selected and studied in depth, considering two aspects: to be representative of the state mesoregions and to indicate transversal contents: educational trajectory, life projects, profession and future. This study points out that the school has a function beyond formal learning, consisting of a space of leisure and coexistence, of construction of identifications and also of projection for the future beyond the professional field, however, also evidences the lack of a work of particularized orientation to those youths.
\end{abstract}

Keywords: Youth; vital project; rural populations

\section{Juventud femenina del medio rural: sentidos sobre educación y perspectivas sobre futuro}

\section{Resumen}

Este artículo tiene como objetivo promover reflexiones a respecto de la educación y de las perspectivas de futuro de jóvenes mujeres del medio rural residentes en distintos municipios del interior de Rio Grande do Sul, Brasil. Se realizaron entrevistas y composiciones fotográficas, ambas entendidas como producciones narrativas, con cuarenta y ocho jóvenes. Siguiendo un proceso analítico basado en los presupuestos de la Teoría Fundamentada, siete entrevistas fueron seleccionadas y estudiadas en profundidad, teniendo en vista dos aspectos: ser representativas de las mesorregiones del estado e indicar contenidos transversales: trayectoria educacional, proyectos de vida, profesión y futuro. Este estudio apunta que la escuela desempeña una función para más allá del aprendizaje formal, consistiendo en un espacio de ocio y de convivencia, de construcción de identificaciones y también de proyección para el futuro para más allá del campo profesional, sin embargo, también evidencia la falta de un trabajo de orientación particularizado a esas juventudes.

Palabras clave: Jóvenes; proyecto vital; populación rural. 


\section{Introdução}

O presente artigo analisa os sentidos ${ }^{1}$ que jovens muIheres do meio rural conferem à sua educação, bem como os planos que estas jovens têm em relação ao futuro através da análise de suas narrativas (orais e visuais - entrevistas e produção de fotografias) sobre educação, trabalho e contexto sócio-cultural. O objetivo central da abordagem foi promover reflexões sobre os processos de trajetória e expectativas de projeto vital de jovens mulheres de diferentes realidades rurais. A partir de pesquisa realizada com 48 jovens, foram selecionadas narrativas de sete adolescentes, com idades entre 14 e 17 anos e residentes de diferentes municípios no interior do Rio Grande do Sul. A escolha desse público se fundamentou na representatividade geográfica (cada uma de determinada mesorregião do estado que compôs o estudo) e na completude da narrativa, ou seja, de cada localidade foi escolhida a entrevista que abordou os temas transversais de forma mais ampla.

Partimos do pressuposto de que analisar narrativas sobre educação e trabalho pode ser uma tarefa importante na compreensão das trajetórias de vida, em contextos de pluralidade de referenciais culturais (Bruner, 1997). É por meio da análise de narrativas de jovens em processo de construção de novas possibilidades de si e, seus processos de autoria e significação/interpretação coletiva que se pretende identificar como as narrativas sobre suas trajetórias educacionais e projetos vitais/ocupacionais apontam possibilidades de criação de si-mesmas. O percorrido teórico parte de algumas concepções sobre adolescência e juventude, escola e educação, apontando no decorrer do texto especificidades sobre o jovem do meio rural, além de refletir sobre as interferências que o sistema capitalista causa em seus modos de ser e de criar.

Ainda que a adolescência possa estar atrelada às transformações fisiológicas que caracterizam a puberdade (Pratta \& Santos, 2007), a juventude vai além de um fenômeno de mudanças corporais, sendo atravessada por questões mais amplas de ordem social, cultural e histórica. Ou seja, cada contexto possui idiossincrasias, pois estas elaborações embasadas nas mudanças biológicas e sociais são variantes em diversos grupos, influenciam nas identificações, nas normatizações e aberturas de possibilidades nos processos de subjetivação (Lopes de Oliveira, 2006). A adolescência pode ser entendida como uma criação da sociedade moderna, sendo uma das formações culturais mais fortes de nossa época. É um conceito sustentado pelo imaginário social que, sob uma perspectiva, está associada como possibilidade de resgate da liberdade dos adultos e,

\footnotetext{
1 O sentido, dentro de umas perspectiva sócio-histórica, pode ser concebido como a parte reflexiva da consciência, não consistindo em uma estrutura psicológica concreta, na medida em que pode assumir diferentes formas e manifestações e, consequentemente, produzir diferentes efeitos psicológicos. O sentido está atrelado à parte subjetiva do significado, o que significa que não contempla somente a consciência individual, mas tem também um caráter social, relacional e cultural (Neliubin, 2009).
}

por outro lado, é concebida como ameaça, violência e desordem (Calligaris, 2009).

A ideia de adolescência como fruto de um processo sócio-histórico, depende de variáveis contextuais, relacionadas às da cultura majoritária, onde gênero e diferenciação social criam assim diversas formas de conceber a adolescência (Martins, Trindade, \& Almeida, 2003). Pensar a construção dessa etapa da vida em áreas rurais significa contemplar as especificidades impostas pelo meio, a exemplo da distância de serviços de saúde e instituições de ensino que os jovens do meio rural enfrentam como desafios diários. Estes fatores podem, inclusive, intensificar as probabilidades relativas a comportamentos de risco, podendo perdurar na vida adulta e acarretar problemas significativos tanto em relação à saúde mental e quanto à possibilidade de assunção de novos papéis sociais (Collins, Tinkwen, \& Logan, 2008; Lama, Fernandez, \& Léon, 2002). Essa possibilidade de assunção de atribuições sociais e de ressignificação de possibilidades existenciais pode ser identificada na construção de trajetórias vitais e projetos de vida na transição para a juventude.

Em relação aos projetos de vida, os jovens percebem que as diferenças entre a vida na cidade e no campo não dizem respeito apenas ao tipo de projeto de vida especificamente, mas sim nas formas para alcançá-lo, colocá-lo em prática (Furlani \& Bomfim, 2010). Isso se daria através da diversidade de oportunidades que a cidade muitas vezes tem e o campo não possui, como universidades e outras formas de trabalho que não sejam atividades estritamente do âmbito rural, ou seja, os múltiplos ambientes que a cidade oferece (Furlani \& Bomfim, 2010). Pode ser referido ainda que os ideais de urbanidade colorem os processos de significação dos projetos de vida destes diversos jovens.

Este ideal de urbanidade acaba sendo reforçado pelos diferentes discursos sociais e também pelas pesquisas acadêmicas, a exemplo do que acontece na área da psicologia, a qual, apesar de todo engajamento político de que se reveste, segue a concepção da vida no campo a partir de uma negativa ao urbano, o que significa pensar que o rural só é contemplado a partir da oposição ao espaço urbano, este último ligado ao desenvolvimento e ao progresso (Martins, 2010). Rodrigues e Baptista (2010) apontam ainda que o projeto das grandes metrópoles, logo após o ápice da revolução industrial influenciou o ideário da ruralidade como atraso e a vida comunitária como primitiva. De fato, diversas disciplinas acadêmicas orientaram suas pressuposições de forma a considerar o espaço rural como rústico e menos desenvolvido, carregando assim para a urbanidade o status de ideal de desenvolvimento, sendo o trabalho assalariado e a constituição de família como o projeto padrão e naturalizado como meta civilizatória ocidental.

O rural é normalmente descrito a partir de duas perspectivas: uma visão romântica que o atrela a um local idílico e bucólico e outra visão de pobreza e carência cultural, a qual associa o campo como um local de atraso, povoado por sujeitos analfabetos e ignorantes (Martins, 2010). Neste sentido, a figura do meio rural acaba por ser a personificação 
dessa dualidade, motivo pelo qual sua representação social é geralmente distorcida (Paulilo, 2004). Entretanto, não há a necessária oposição entre urbanidade e ruralidade e sim uma relação de continuidade, de complementariedade, posto que a vida no meio urbano depende também do trabalho no campo e, intercambia valores e perspectivas existenciais em uma mesma sociedade capitalista. A educação no meio rural, como política pública, segue esta relação de reciprocidade, na medida em que apresenta também as problemáticas e desafios da educação como política pública, de alguma forma promovendo e intensificando desigualdades, uma vez que homogeneíza as perspectivas curriculares, independentemente do contexto em que se propõe a formar (Sikora, Hidalgo, \& Junior, 2015).

A aproximação e apropriação da ruralidade pela Psicologia torna-se, desta forma, importante ferramenta na busca por desmistificar as questões relativas ao tema, posto que a análise do contexto rural é multifatorial, não estando atrelada somente à referenciais econômicos ou de escolaridade formal. Os elementos psicossociais também precisam ser contemplados, na medida em que estão em constante articulação com os elementos sócio-históricos, econômicos, políticos e ideológicos que atravessam a vida no campo, suas representações sociais e desafios (Landini, Long, Leeuwis, \& Murtagh, 2014).

Em uma pesquisa realizada em contexto similar do interior do Rio Grande do Sul, Borges (2014) buscou compreender a visão que os próprios jovens têm sobre a adolescência, investigando a existência de diferenças e aproximações a partir dos contextos urbano e rural. Para a autora, embora o jovem do meio urbano partilhe características com o do meio rural - questão que está associada à construção social de um perfil homogêneo - existem diferenças contextuais importantes, como as perspectivas de trajetória de vida e as redes de socialização engendradas.

Em estudo comparativo entre adolescentes do meio rural e do meio urbano, Martins, Trindade e Almeida (2003) apontam que, para os jovens rurais, o plano de adultez inicia ou termina com o ensino médio, já que este é geralmente o máximo de escolarização alcançada nesse contexto. Ao contrário, jovens localizados no contexto urbano, veem o futuro como algo posterior à universidade, tendo assim um alargamento do tempo das decisões que ritualizam a passagem à vida adulta. Além disso, jovens do meio urbano preocupam-se mais com atividades de lazer e a criação de uma rede de amigos, já os adolescentes do meio rural, tem a necessidade e a responsabilidade de uma certeza a ser trilhada em sua trajetória para a vida adulta. Para Castro (2009), existe ainda uma contradição na visão que temos sobre o jovem: se por um lado, ele é visto como herói, como protagonista agente de transformações sociais, como o futuro de uma nação, por outro lado, existe um olhar que associa o jovem à delinquência, às drogas e aos problemas sociais.

É importante demarcar que as representações sociais acerca do jovem no meio rural são atravessadas por questões de gênero e que estão não somente atreladas à desvalorização social do trabalho feminino - característica compartilhada com muitos contextos em nossa sociedade como também à consequente posição econômica desigual que a mulher ocupa. Além disso, o fato de que o acesso das mulheres à terra é menor do que o dos homens e que elas são também discriminadas nas políticas públicas voltadas à agricultura familiar mobiliza a necessidade de nos aproximarmos com maior clareza de seus projetos ocupacionais e do papel que a escola desempenha na construção deste (Paulilo, 2004).

Considerando que as adolescentes que participaram da pesquisa estavam cursando o ensino médio, ao realizarmos uma breve contextualização sobre o papel da escola e os sentidos da educação na vida dos adolescentes, traremos algumas questões teóricas acerca do ensino médio no Brasil. Frigotto (2010) entende que qualquer análise que seja feita sobre o ensino de nível médio no Brasil precisa incluir elementos mais amplos sobre o sistema de ensino como um todo, considerando que os problemas encontrados neste nível de ensino são parte de problemas educacionais estruturais. $\mathrm{O}$ acesso à escola não garante, por si, educação de qualidade.

Para Frigotto (2004) alguns aspectos contribuem para a desqualificação dos processos educacionais oferecidos no âmbito das escolas públicas. Um deles diz respeito ao fato da escola ser dual, ou seja, funcionar de acordo com a classe social. Outro fator remete ao desmonte da escola básica, a qual é tratada com menor valorização, como filantropia e assistencialismo, não sendo concebida de acordo com o que preconiza a Constituição Federal de 1988 (1988) ou seja, como um direito a ser assegurado a todos.

Entendemos que outro elemento também auxilia na compreensão da educação ofertada aos jovens, o qual diz respeito à adoção de práticas educativas pautadas na lógica neoliberal através da chamada pedagogia das competências. Uma educação imbuída na perspectiva da meritocracia e que acaba atendendo aos interesses do capital, disseminando a ideia de que, já que não terá lugar para todos, somente terão sucesso profissional os melhores, aqueles que fizerem por merecer (Moura, 2013). Concomitantemente, o ensino médio, por exemplo, sofre uma brutal fragmentação de conteúdos, que destinam seu enfoque para nomes, fórmulas e classificações, se limitando em detalhes pouco vinculados aos contextos vivenciais dos jovens, especialmente os de contextos culturalmente marginalizados. Essa fragmentação resulta em um currículo extenso e em um distanciamento das realidades de vida e dos trabalhos dos estudantes, que acabam afastados de uma formação mais ampla que lhes apresente os princípios básicos da produção do conhecimento das ciências e da tecnologia e consiga integrá-los em um projeto de formação maior, que contemple a vida para além do espaço escolar imediato.

Considerando que a proposta do artigo é refletir sobre os sentidos da educação e as perspectivas de futuro de jovens que vivem no meio rural, além de buscarmos fundamentação teórica a respeito da temática que envolve o processo de investigação, é também necessário tornar claro de que forma os depoimentos das jovens que participaram 
da pesquisa serão trabalhados, buscando uma interlocução teórico-prática. Neste sentido, partimos para uma explanação a respeito da orientação metodológica da investigação realizada.

\section{Método}

Este artigo apresenta uma análise qualitativa de dados gerados por meio de entrevistas narrativas e produção de imagens fotográficas de sete participantes de um grupo de 48 jovens. Essas narrativas foram selecionadas tendo em vista que eram as que melhor sintetizavam as temáticas relativas ao percurso de pesquisa de cada uma das sete localidades (escolhidas intencionalmente, por possibilidade logística) que representava cada uma das sete mesorregiões ${ }^{2}$ do estado que compôs a pesquisa. As jovens tinham entre 14 e 17 anos e cursavam o ensino médio em escolas de sete municípios do interior do Estado do Rio Grande do Sul. As participantes da pesquisa foram contatadas através de escolas públicas de zonas rurais de agricultura familiar do Rio Grande do Sul, ou em dois casos, escolas localizadas em sedes municipais de pequenos municípios que atendiam, particularmente, alunos de origem rural. Além de contar com o aval de tais instituições (contatadas por amostragem intencional, via secretarias municipais de educação) e dos responsáveis pelas jovens, o critério de inclusão foi o de que as alunas estivessem matriculadas em escolas rurais ou que fossem moradoras da zona rural dos municípios. Considerando que se tratam de localidades de pequenos municípios, por questões éticas, consideramos mais adequado omitir essa informação da caracterização dos resultados.

Todas as jovens convidadas aceitaram participar, ainda que cinco delas acabassem desistindo no percurso. Foi fundamental nesse processo de coleta o apoio logístico das escolas, que nos enviavam as máquinas fotográficas para revelação. Evidentemente se assume o viés de desejabilidade que essa estratégia pode ter causado entre as participantes, mas, sem tal operação, a coleta seria mais complicada. O projeto de pesquisa foi analisado e aprovado pelo Comitê de Ética em Pesquisa com Seres Humanos da PUCRS (11/05325).

Foram realizadas entrevistas orientadas às seguintes questões de pesquisa: Como se constroem os projetos vitais e profissionais destas jovens? Como percebem o contexto sócio-cultural em que estão inseridas? No primeiro momento, a entrevista abarcava aproximações ao cotidiano das adolescentes, como eram percebidas suas relações com a escola, com a comunidade em que vivem e com sua família. Ainda nesta primeira etapa, máquinas fotográficas descartáveis foram entregues juntamente com um roteiro para elaboração de fotos, entre os itens que estavam enu-

2 Segundo divisão definida pelo IBGE, o Rio Grande do Sul - RS possui sete mesorregiões - Nordeste Rio-grandense; Noroeste Rio-grandense; Centro Ocidental Rio-grandense; Centro Oriental Rio-grandense; Metropolitana de Porto Alegre; Sudoeste Riograndense; Sudeste Rio-grandense (Fialkov, 2014). merados, escolhemos para a presente análise: 1) Trajetória Educacional; 2) Projeto de vida, 3) Profissão e 4) Futuro, totalizando 28 fotografias. A segunda entrevista foi realizada a partir das fotos produzidas pelas participantes, onde cada item foi discutido pelo entrevistador e pela participante, com o objetivo de compreender as escolhas feitas no momento da produção da foto. Assim, o corpus geral de análise ficou composto por 14 entrevistas (duas com cada participante) e 28 fotografias (quatro de cada participante).

Segundo Banks (2009), a produção de narrativas visuais se define como uma organização intencional de informações; dessa maneira, os materiais podem ser entendidos como estruturas comunicativas. Nesse sentido foi proposto que, além de elaborar considerações sobre as fotografias isoladamente, o entrevistado estabelecesse sentidos para a construção da série fotográfica como um todo, estabelecendo ordens de importância, cronológica, etc. para sua produção. Este método de produção fotográfica pareceu despertar envolvimento e uma postura ativa nas participantes da pesquisa.

Optamos pela perspectiva narrativa de entrevistas e produções visuais já que ela possibilita uma profundidade na obtenção de dados, pois, segundo Jovchelovitch e Bauer (2002) concebe-se a narrativa como uma atividade capaz de organizar eventos em uma totalidade repleta de sentidos próprios daquele sujeito, desvelando os significados que suas experiências e ideias possuem, através de um panorama cultural. Neste sentido, ressalta-se a complementaridade que a fotocomposição possui neste projeto, pois opera como uma forma de apreensão da significação que participantes dos estudos fazem de seus espaços e vidas, e sua escolha se deve a seu potencial como forma alternativa de linguagem em pesquisa (Maurente \& Tittoni, 2007). Segundo Fontcuberta, (2013), a fotografia é a manipulação da realidade, é a transformação ativa de um determinado contexto através da significação de seu autor. Fotografar, portanto, é mais uma maneira de os sujeitos construírem suas realidades ampliando as ferramentas de expressão para além das palavras escritas e faladas.

Para análise do material coletado, foram adotados os pressupostos da Teoria Fundamentada (Charmaz, 2009), método que pretende dar diretrizes para a interpretação dos dados, cujos dispositivos heurísticos são orientados para a elaboração da experiência específica que está sendo estudada. Assim, busca-se utilizar os termos e temáticas evidenciadas no próprio campo de pesquisa, evitando códigos pré-concebidos, ao mesmo tempo em que se procura gerar teorias que possam ser transpostas para as experiências semelhantes, mas em outros contextos (Charmaz, 2009). Teoria, nesta perspectiva metodológica, compreende um conjunto de temáticas ou eixos analíticos que tenham a capacidade de sintetizar o fenômeno estudado, sempre tendo em vista que trata-se de uma co-construção entre interlocutores, e não numa dualidade pesquisadores(as)/ pesquisados(as).

Segundo Strauss e Corbin (2008), a Teoria fundamentada é composta por diferentes etapas. A criação de 
Ordenamentos Conceituais, passa por três momentos: a codificação aberta, onde os dados discursivos são agrupados segundo temáticas gerais, por vezes este procedimento já ordena algumas classificações e pré-codificações. No seguinte momento, alguns eixos são elencados a partir dos temas mais gerais, buscando especificidades da experiência estudada. O terceiro e último momento é o da Teorização, em que o pesquisador busca criativamente sistematizar as idéias e elaborar a teoria explicativa de determinada realidade. Assim, ele utiliza-se dos conceitos criados na fase anterior como dispositivos heurísticos orientados para aprimorar suas especulações e finalmente criar a Teoria Fundamentada nos Dados (Charmaz, 2009; Garay \& cols., 2002). A partir destes movimentos, aspectos linguísticos ou termos não acadêmicos podem ser elencados como forma de dar visibilidade para uma construção singular em pesquisa.

O trajeto de análise dos materiais apresentados seguiu os preceitos acima assinalados, ocorrendo, num primeiro momento, por dois pesquisadores de forma independente, que selecionaram materiais considerando o que seria pertinente para a discussão proposta. Este primeiro momento deu origem a seleção das sete narrativas que mais sintetizavam aspectos da experiência em pesquisa. No segundo momento, a seleção do material foi compartilhada pelos autores, para seleção dos excertos mais específicos, que fossem de comum acordo, alinhavando as temáticas gerais e a codificação específica. A última etapa, a da teorização propriamente dita, foi realizada em conjunto, buscando assim dar organicidade ao processo de análise e escrita do presente artigo.

Buscando dar visibilidade às narrativas das participantes da pesquisa, selecionamos alguns trechos de seus depoimentos a partir dos eixos já citados, a saber: trajetória educacional, projetos de vida, profissão e futuro. Abaixo, apresentamos os resultados das reflexões e indagações do presente estudo.

\section{Resultados e discussão}

\section{Trajetória Educacional}

Em relação ao eixo "Trajetória Educacional", a fala das adolescentes que participaram da pesquisa remete sempre à figura da escola. As entrevistadas referiram encontrar algumas dificuldades para manterem-se frequentes na escola, incluindo a distância geográfica entre suas casas e as instituições escolares que freqüentam. Por serem moradoras do meio rural, tinham que doar considerável tempo de seus dias para o deslocamento até a escola. Mesmo com este desafio diário, esta organização desempenha um papel de suma importância em suas vidas, sendo parte de seus projetos e expectativas desde a infância. "Às vezes eu era pequeninha e via o meu irmão indo pra escola, aí eu chorava porque queria ir junto, mas não dava, não tinha idade". (Carine, 16 anos)
... porque sem estudo eu não teria um futuro bom. E que não podia perder aula. Até quando eu perdia o ônibus ou dormia até mais tarde, eu chorava (risos). Porque não podia perder aula (risos). (Carolina, 14 anos)

Ainda em relação à escola, as falas das entrevistadas apontam que esta organização está vinculada não somente aos processos formais de aprendizagem, compondo um espaço de lazer, de integração através do convívio com os colegas e de afetividade. "Mas a minha maior diversão é o colégio. Que eu tenho as minhas amigas, aí eu converso, eu dou risada" (Andrieli,14 anos).

A educação é a escola, mas não vem diretamente da escola
a educação também, tem que vir mais é de casa, a escola é
só um complemento a mais pro conhecimento das pessoas.
Aí eu tirei da escola que também ajuda na educação (Carine,
16 anos).

Sugerimos a relação das jovens com a escola como dimensão que possibilita uma educação para além do conteúdo formal, preenchendo espaços de convivência comunitária preponderante na vida dessas jovens considerando a falta de opções de lazer, aspecto indicado na literatura como importante quando os(as) jovens refletem sobre a vida no campo (Zago, 2016). Conforme aponta uma das entrevistadas:

De sair também, acho que eu sinto falta, de ver algum evento, assim, alguma coisa. Não tem lugar que seja especificado para jovem aqui... Aqui também, tipo, a informática, o celular, essas coisas, é bem complicado porque tem que ter lugares pra ti conseguir falar com alguém, não é a hora que tu quer. (Fernanda, 14 anos).

Foi possível perceber também que existe uma relação forte entre o papel que a educação e a escola desempenham na vida destas adolescentes e o nível de instrução ou atividade profissional de seus pais ou responsáveis. Ficou evidente que a importância que atribuem à escola e à educação em suas vidas se relaciona com as trajetórias dos pais e mães, que tiveram poucas oportunidades quando tinham idade escolar. A maior parte dos pais e mães trabalha no campo e têm menos escolaridade do que as filhas têm hoje, reiterando a elas a importância da escolarização para ter outras escolhas.

A minha mãe fala que a escola é bom, ter estudo, meu pai também: tu nunca deixa de estudar por coisas. Sempre meu pai e minha mãe diziam: "tem que estudar" (Carine, 16 anos).

A minha mãe vende, é vendedora de umas coisas que ela compra aqui na cidade e vende lá fora, de uma loja. E o meu pai trabalha de empregado numa fazenda. E a minha fala assim: o que eu podia dar pra vocês, que é dar o apoio de ir pro colégio, e agora é com vocês. Eu to tentando dar o que eu nunca pude ter, que é educação, essas coisas. (Ana Lúcia, 15 anos). 
Segundo Zago (2016), a família do campo tem passado por transformações importantes em sua dinâmica, em especial se consideramos a perda de autonomia dos(as) agricultores(as) diante do capital financeiro e da agroindústria e a criação de outras formas de empregabilidade. Neste sentido, a permanência dos filhos na escola representa a possibilidade de empregos fora do circuito de produção agrícola, que é usualmente significado como sinônimo de vida dura e sofrida (Carvalho \& cols., 2009). Estes aspectos, nas narrativas apresentadas, se organizam intrinsecamente relacionado com questões geracionais. Há referências às noções de desenvolvimento que a educação formal pode oferecer para estas meninas, apontando que em sua origem, necessitam galgar uma melhor posição, avançar e ter outro tipo de vivência em relação à que seus pais tiveram quando se encontravam em idade escolar. Neste sentido algumas falas são bastante expressivas quanto a isso:

Pretendo não ficar em $X$. [município] porque a cidade é muito parada, não tem desenvolvimento... O pai e a mãe poderem dizer: ah, o que eu fiz pela Lilian, ah... Ter de volta, sabe? O que eu dei pra ela, ela conseguiu fazer dela uma boa coisa. Tipo, arrumar um emprego, ter uma casa, ter uma família direito, sabe? É mais ou menos isso (Lilian, 17 anos).

A Figura 1, por exemplo ilustra algumas das fotografias feitas pelas participantes. Ao referirem-se à escola ou à sua trajetória educacional, materializaram na escola "real" a imagem dessa trajetória. Se, por um lado, as fotografias indicam a precariedade de seus espaços físicos educacionais, quando integradas com as entrevistas permitem compreender um processo complexo que envolve a escola, enquanto organização. A escola é tomada como espaço de convivência e sociabilidade, e caracterizada, conjuntamente a narrativas orais, como contraponto ao esvaziamento dos espaços públicos da cidade. As fotografias, neste sentido, coadunam aspectos como o acesso dificultado as escolas, a importância da organização escolar como espaço de convivência entre jovens e as atribuições deste espaço voltado para a educação (objetos que culturalmente indicam esse fazer como equipamentos, livros etc.).

\section{Projeto de Vida, Profissão e Futuro}

Estes eixos aparecem em constante articulação. As entrevistadas, ao falarem sobre seus sonhos e planos futuros, trazem questões relacionadas à vida profissional, como por exemplo, a possibilidade de realizarem cursos de graduação e assim conseguirem oportunidades no mercado de trabalho que garantam condições de subsistência e de realização de seus projetos de vida. Quando questionadas sobre o que esperam do futuro, uma das jovens relata: "Ah, é passar numa faculdade... Entrar pra uma faculdade. Eu pretendo ser veterinária. Ter meu próprio negócio". (Carine, 16 anos).

A partir das falas das jovens foi possível perceber também que os planos futuros envolvendo estudos e carreira
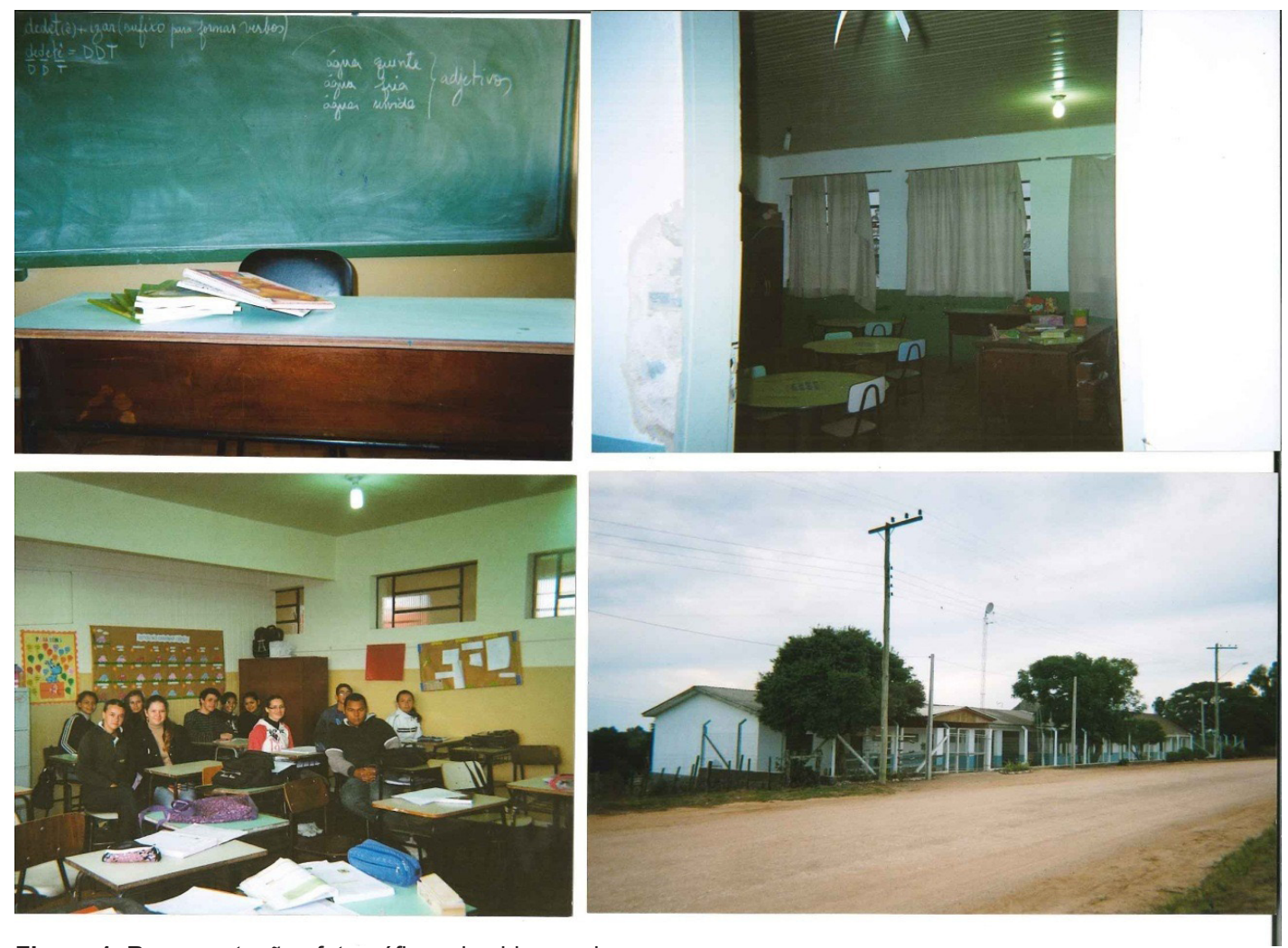

Figura 1. Representações fotográficas da vida escolar. 
profissional, algumas vezes podem significar abrir mão de sonhos em função das demandas da vida e daquilo que é valorizado socialmente em seu contexto, ou seja, do que os pais e a sociedade esperam delas. Uma das adolescentes, ao comentar sobre o sonho de fazer psicologia, complementou:

Tipo, a gente foi na UFRGS agora esses dias, aí eu fui nas palestras de psicologia e eles falaram que é bom e tal, quem gosta vai e faz, só que um psicólogo, dá tipo um chute numa moita e sai vinte. E emprego também é bem difícil e eu penso que eu quero um trabalho que me sustente futuramente. Isso que eu penso às vezes, mas futuramente eu quero fazer direito" (Lilian, 17 anos).

Eu pretendo ser veterinária. Tipo, eu pretendo fazer em Santa Maria. Aí eu começo, faço e aí eu termino. Começo a fazer estágio. Mas tipo, tem as minhas tias que disseram que é muito difícil, as vagas são difíceis. Mas eu não vou desistir (Ana Lúcia, 15 anos).

Há, além das referências ao futuro e a obrigatoriedade de exercer uma profissão, a idéia de competitividade atrelada à escolha e as características da vida adulta. Ressalta-se assim a condição básica de um sistema capitalista e a relação que os trabalhadores autônomos estabelecem com o sistema e com sua categoria, a de que há uma dificuldade em exercer a profissão pelo alto nível de procura e pela natureza da própria atividade, algo que exige muito esforço e envolve percalços.

Ainda em relação ao eixo "Futuro", as falas das entrevistadas remetem a uma associação bastante intensa em conseguir um bom trabalho, especialmente um trabalho que permita o próprio sustento do ponto de vista financeiro e a mudança para outra cidade.

O meu futuro depende um pouco de mim e outro não, como eu te falei. Eu acho que como eu teria que me mudar, como eu teria que trabalhar em outra área eu acho que meu futuro foi difícil pra tirar foto mesmo, foi mesmo complicado. Teria que ir pra outro lugar (Fernanda, 14 anos).

Eu penso que eu termino aqui, eu vou embora e só pretendo voltar pra ver meus pais. Não pretendo voltar pra cá pra morar. Porque...É, sei lá... É cidade pequena. Então tipo, emprego é pouco, sabe? (Ana Lúcia, 15 anos).

Outra participante, ao referir que vai mudar de cidade para buscar seu futuro profissional, argumenta: "É que eu quero passar na federal' (Camila,16 anos)

A Figura 2 integra algumas fotografias representativas das narrativas sobre futuro, onde se destacaram imagens de formaturas formais, o edifício de uma Universidade de uma cidade próxima (que a participante visitou com a família) e, muitas fotografias que apresentam símbolos de evasão do
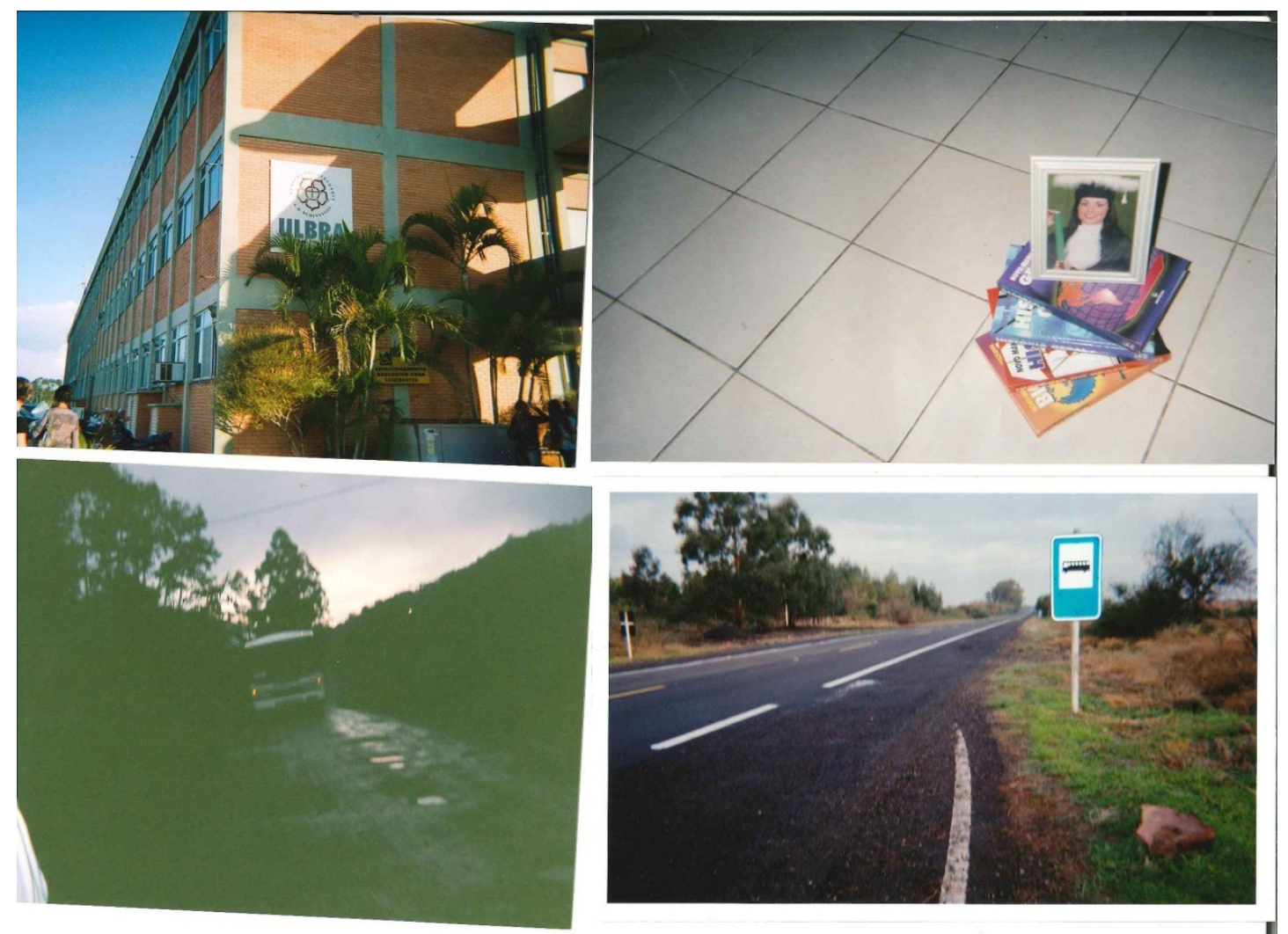

Figura 2. Representações fotográficas das expectativas de futuro. 
espaço rural, como fotos das estradas, rodovias, ônibus e paradas de ônibus. O futuro está na cidade.

As participantes relataram que, para terem acesso à educação de nível superior e a boas oportunidades profissionais, por exemplo, precisam migrar do meio rural para os centros urbanos. Levantamos aqui também uma questão sobre a noção de desenvolvimento que remete a um ideal de urbanização, pois as adolescentes entrevistadas referenciam que o meio rural é menos desenvolvido, e assim, menos propício a oferecer oportunidades de crescimento profissional.

O ideal de urbanização está atrelado à possibilidade de remuneração, e ressaltamos que o cotidiano capitalista canaliza os esforços e relações de uma forma monetarizada. Isto quer dizer que se coloca a mediação do dinheiro em todas as facetas do cotidiano, e que as possibilidades de exercício de si mesmo estão baseadas em qual atividade pode fornecer a melhor remuneração e uma projeção de futuro centrado na escolha profissional.

As adolescentes, sendo parte do contexto em que estão inseridas, acabam pautando suas escolhas futuras a partir de bons salários ou profissões e cargos que tragam repercussão de reconhecimento. Além disso, o assalariamento parece ser um elemento importante aqui levantado, minimizando outras formas de autonomia de renda ou mesmo em uma outra linguagem de empreendedorismo conectado ao meio rural. Quando cabe alguma consideração mais autônoma, está situada em um ideal urbano. Este aspecto reitera questões indicadas em outras pesquisas, no qual o trabalho urbano é valorizado por ser compreendido como fonte de renda mais segura (Castro, 2016). Entretanto, também se salienta que essa compreensão relaciona-se à instabilidade e precariedade muitas vezes vivenciadas nas áreas rurais, em especial no que concerne ao investimento do estatal em negócios familiares.

Cabe aqui mencionarmos algumas reflexões do filósofo Dufour (2005) a respeito das consequências que a lógica capitalista traz para a vida, ao postular que vivemos uma crise de falta de referenciais dificultando nossa constituição enquanto sujeitos. O referido autor entende que os jovens são os que mais sofrem com isso, posto que, por sua condição de estarem em pleno processo de desenvolvimento, acabam sendo a parcela mais exposta da sociedade a esta falta de referências. Dufour (2005) entende que esta crise é causada em grande parte pelo sistema capitalista, posto que a lógica de troca mercadológica tende a dessimbolizar o mundo. O ser humano, nesta perspectiva, acaba transformando-se também em uma mercadoria a ser consumida, em outras palavras, ficando a mercê a todas as conexões mercadológicas, como "um vazio aberto a todos os ventos" (p.22).

Nesta direção, foi possível perceber que a rotina diária envolve não somente atividades escolares, mas atividades laborais, em sua maioria tarefas domésticas e o trabalho no campo, na lavoura. Conforme já apontado, verificou-se que estas atividades, embora demandem tempo e investimento por parte das adolescentes, não são valorizadas em comparação com um trabalho remunerado. Assim, levantamos novamente o questionamento a partir da legitimação e valorização das atividades do meio rural, fato que acaba sendo intensificado pela lógica do sistema capitalista urbanocêntrico, ou seja, tem valor aquilo que é passível de ser contabilizado em termos monetários e segundo a lógica das urbes. Algumas falas exemplificam esta questão, como por exemplo:

Depois acordo, faço os temas (tarefas escolares), ajeito um pouco meu quarto pra não ficar aquela bagunça e daí depois vou ajudar a mãe, por exemplo, como eu disse, dar água pros porcos, tocar os terneiro, limpar a casa, depois de noite ajudo a fazer janta, assisto um pouco de TV, né, e em torno das dez e meia eu vou deitar. (Carolina, 14 anos).

A gente estuda, mas trabalha também. De manhã eu trabalho na lavoura (Andrielli, 14 anos)

Quando questionadas sobre sonhos, a trajetória profissional é novamente apresentada como um ideal a ser construído, inclusive sendo prioritário em comparação com outras possibilidades como, por exemplo a constituição de uma família:

Ah, porque eu penso mais nos meus estudos. No meu conhecimento, na minha vida profissional. Família a gente consegue depois. A gente já tem a nossa, depois a gente consegue arrumar. Mas primeiro os estudos, não pode deixar. Parar de estudar porque quero ter a minha família, não! (Carine, 16 anos).

Trabalhando, realizada profissionalmente e ter uma vida estável viajando... eu gosto muito de viajar, e acho que talvez, começar a pensar em constituir uma família, mas em primeiro lugar se estabelecer (Camila, 16 anos).

Em relação à juventude, podemos pensar a partir dos relatos das entrevistadas que, muito provavelmente, a busca de encontrar um lugar no mundo, em sintonia com as contribuições teóricas de Rassial (1997), talvez possa ser ainda mais desafiadora para as adolescentes residentes no meio rural. Embora o referido autor aponte o processo de encontrar-se enquanto sujeito capaz de responder por suas escolhas e atitudes desde um ponto de vista simbólico (Rassial, 1999), pensamos que para as participantes da pesquisa soma-se a este fato a falta de referenciais também no lugar geográfico em que vivem. Em outras palavras, para as entrevistadas, além da incerteza em relação às suas escolhas e perspectivas futuras, existe também uma falta de espaço-tempo para o lazer. Ainda que a legislação preconize esta vivência como um direito a ser garantido, o que inclui a convivência com o grupo de iguais para além do espaço de convívio proporcionado pela escola para viver as especificidades do período da vida que atravessam, isto não acontece de fato nas experiências das jovens entrevistadas.

Outras dificuldades que as entrevistas apontam dizem respeito à dificuldade no acesso a instituições educativas de qualidade ou mesmo outros serviços vinculados 
a outras políticas públicas, todas elas relativas a direitos básicos documentados nos Estatutos da Criança e do Adolescente (Lei $n^{\circ} 8069 / 1990,1990$ ) e da Juventude (Lei $n^{\circ}$ $12852 / 2013,2013)$, a exemplo de serviços de saúde. Ao encontro do que postulam Martins, Trindade e Almeira (2003), existem especificidades quando nos referimos a adolescentes que vivem no meio rural, sendo uma delas a distância no acesso aos serviços acima descritos. Não é por acaso que as falas apontam para a necessidade de saírem de suas cidades de origem em busca de futuro melhor, estando este fato vinculado a oportunidades de acesso a instituições de ensino de qualidade ou ainda na possibilidade de garantir uma colocação no mercado de trabalho que reverta em retorno financeiro.

De fato, o acesso à escola no meio rural tem especificidades que precisam estar contempladas em qualquer análise sobre a educação neste contexto. Uma delas diz respeito a que muitos daqueles que deveriam estar dedicando seu tempo a estudar e conviver com grupo de iguais estão trabalhando para auxiliar na produtividade da família, deixando para ir à escola somente em seus momentos de folga. Ainda, as dificuldades estruturais das escolas no campo somam-se à distância geográfica que grande destas apresenta em relação aos locais de moradia dos estudantes (Sikora, Hidalgo, \& Junior, 2015).

De acordo com Borges (2014), alertando para as especificidades características do jovem rural, as falas das participantes apontam para um processo de homogeneização da adolescência, o que significa a crença na premissa de que existiria uma única forma de viver este período do ciclo vital. Neste sentido, todas precisam residir em grandes centros urbanos, buscar formação superior em universidades e conseguir bons empregos. Só depois de estabelecidas profissionalmente, pensar em constituir uma família ou realizar outros projetos de vida.

No que diz respeito à educação, embora esta área ainda enfrente problemas estruturais significativos (Frigotto, 2010), especialmente no que diz respeito à desvalorização dos níveis básicos de ensino, foi possível perceber que a escola desempenha importante papel na vida das adolescentes do meio rural, funcionando não apenas como um espaço onde acontecem os processos formais de aprendizagem, mas sendo também um suporte importante no que diz respeito ao convívio, à integração, ao estabelecimento de laços afetivos e à vivência de momentos de lazer.

Ao assumir posições de questionamento, as mulheres do âmbito rural tensionam o cerne da agricultura naquele espaço, ou seja, a família. Aparentemente o trabalho e a manutenção da propriedade na agricultura familiar são o principal aglutinador identitário de seus membros, mesmo que sejam profundamente assimétricos em relação às expectativas de gênero. A disparidade entre os papéis atribuídos ao homem e à mulher repercute nas trajetórias de vida destes: enquanto que os homens ainda detêm poder decisório sobre os rumos da produção e são vistos como herdeiros naturais da propriedade e na continuidade do trabalho exercido, as mulheres, por sua vez, estão ausentes dessas discussões e tendem a buscar novos rumos em suas vidas, inclusive no que diz respeito ao casamento ou à formação educacional (Strapasolas, 2004; Castro, 2016).

A escolaridade se pronuncia como fator importante nesse rompimento com o modelo de relacionamento tradicional, assim as mulheres apresentam maior escolaridade que os homens, e convertem esse aspecto de suas vidas como potencializador de outros rumos profissionais e de relacionamento, vinculados em sua maioria a experiências na cidade (Stropasolas, 2004). Os dados da migração rural-urbana corroboram as perspectivas levantadas por Stropasolas (2004). Partindo de análises quantitativas e qualitativas, Brumer (2004) também conclui que as mulheres migram para as cidades acentuadamente mais do que os homens. A causa desse processo migratório de mulheres estaria, entre outros aspectos, justificada pelas desigualdades de gênero associadas ao trabalho e à propriedade que estas ainda enfrentam.

\section{Considerações Finais}

Buscamos compreender, por meio das falas das entrevistadas, quais seriam os sentidos que tem a educação para jovens mulheres do meio rural, bem como suas perspectivas em relação ao futuro. Compreendemos o processo por meio de questões contextuais amplas, apontando como o sistema capitalista e suas questões estruturais fazem parte das escolhas de projetos de vida e que não estão explicitamente referenciadas. Assim, organizamos nossa análise na perspectiva de identificar pontos críticos, onde a pesquisa pudesse contribuir para a compreensão do fenômeno, bem como apontar novas perspectivas. Mesmo tratando-se de um estudo exploratório preliminar, o que não permite e nem idealiza generalizações, o estudo indica a manutenção de um afastamento das políticas educacionais para o meio rural, seja da realidade contextual, seja da preparação para um projeto vital que não passe pelo caminho universitário.

Considerando a questão do desenvolvimento levantada pelas participantes, poderíamos questionar se o ideal de urbanidade, referenciado anteriormente no artigo, não seria danoso como um modelo de desenvolvimento para a juventude, já que as peculiaridades do contexto rural parecem ser diversas às do meio urbano. Desta forma podemos também questionar se os planos educacionais estão contextualizados, contemplando as especificidades de um local que necessita outros olhares, como a compreensão da dignidade da atividade camponesa, que mesmo sendo fruto de um aprendizado informal, contribui para o desenvolvimento humano.

Em relação aos projetos de vida, o meio rural parece não ser o ideal para as participantes, já que não está organizado de modo a garantir seus direitos de forma efetiva e plena, incluindo espaço e tempo para o lazer, a saúde, o acesso a instituições educativas de qualidade e outras questões básicas. Revela-se então que a urbanidade e a escolha de uma profissão de caráter autônomo simbolizam 
uma condição de sujeito moderno e liberal, um indivíduo que faz por si e que não necessariamente necessita de uma comunidade que o apoie e o forme. Há aposta nas instituições e em uma formação de trabalho que possa remunerar suficientemente para que este indivíduo exerça seu projeto particular, idiossincrático.

Por fim, ressaltamos que as falas ficaram centralizadas no processo de construção de uma narrativa que explicitasse escolhas em um momento de transição, demarcado pela conclusão do ensino médio. As entrevistadas organizaram suas falas através de questões referentes à suas concepções sobre educação, formal e informal, e como esta questão articula-se com a escolha profissional e a organização do projeto de vida.

Ainda que esta, como toda pesquisa qualitativa, não almeje generalizações ou maiores extrapolações a outros contextos, chamam atenção as particularidades do processo educacional de jovens do meio rural. Boa parte das leituras educativo-profissionais das jovens participantes denuncia a falta de um trabalho de orientação particularizado a essas realidades. Aparentemente as orientações predominantes das escolas urbanas, no que se refere a uma formação profissional universitária, têm um eco importante nos processos de construção dos projetos vitais das jovens. Cabe a reflexão sobre a necessidade de orientações educativas que desnaturalizem essas escolhas e tornem mais complexo o leque de opções de projeto de vida à realidade das comunidades não urbanas.

\section{Referências}

Banks, M. (2009). Dados Visuais para Pesquisa Qualitativa. Porto Alegre: Artmed.

Borges, J.L. (2014). Adolescência no contexto rural. Em L.F. Habigzang, E. Diniz, \& S.H. Koller. (Orgs.), Trabalhando com adolescentes: Teoria e intervenção psicológica (pp 144-163). Porto Alegre: Artmed.

Bruner, J. (1997). Atos de Significação. Porto Alegre: Artmed

Brumer, A. (2004). Gênero e agricultura: a situação da mulher na agricultura do Rio Grande do Sul. Estudos Feministas, 12(1), 360.

Carvalho, D.M., Santos, A.B., Souza Jr, J.P.S., \& Ferrer, M.T. (2009). Perspectivas dos jovens rurais: campo versus cidade. Em Congresso da Sociedade Brasileira de Economia, Administração e Sociologia Rural. Anais do $47^{\circ}$ Congresso da Sociedade Brasileira de Economia, Administração e Sociologia Rural. Porto Alegre: SOBER.

Castro, E. (2009). Juventude rural no Brasil: processos de exclusão e a construção de um ator político. Revista Latinoamericana de Ciencias Sociales, Niñez y Juventud, 7(1), 179 - 208.

Castro, F.A.T. (2016). Juventude rural e as contribuições do projeto transformar de capacitação de jovens rurais no Sul de Minas (20062013). Dissertação de Mestrado. Programa de Pós-Graduação em Desenvolvimento Sustentável e Extensão, Universidade Federal de Lavras, Lavras, MG.

Calligaris, C. (2009). A Adolescência. São Paulo: Publifolha.

Charmaz, K. (2009). A Construção da Teoria Fundamentada. Guia prático para Análise Qualitativa. Porto Alegre: Artmed.

Collins, A., Tinkew, J.B., \& Logan, C. (2008). Strategies for improving out-of-school programs in rural communities. Child Trends, 18, 1-8.

Constituição da República Federativa do Brasil (1988). Brasília, DF: Senado Federal.

Dufour, D. (2005). A arte de reduzir as cabeças: sobre a nova servidão na sociedade ultraliberal. Rio de Janeiro: Companhia de Freud.

Fialkov, J. C. (2014). PIB e populações das mesorregiões do Rio Grande do Sul. Recuperado: 04/10/2015. Disponível: http://carta. fee.tche.br/article/pib-e-populacao-nas-mesorregioes-do-riogrande-do-sul-2001-11/.

Fontcuberta, J. (2013). El beso de Judas: Fotografia y Verdad. São Paulo: Ed G. Gili.

Frigotto, G. (2004). Juventude, trabalho e educação no Brasil. Em R. Novaes \& P. Vanucchi. (Orgs.), Juventude e sociedade: trabalho, educação, cultura e participação. São Paulo: Fundação Perseu Abramo.

Frigotto, G. (2010). A relação da educação profissional e tecnológica com a universalização da educação básica. Em J. Moll. (Org.), Educação profissional e tecnológica no Brasil contemporâneo. Porto Alegre: Artmed.

Furlani, D.D. \& Bomfim, Z.A.C. (2010). Juventude e Afetividade: Tecendo projetos de vida pela contrução dos mapas afetivos. Psicologia \& Sociedade, 22(1), 50-59.

Garay, A., Íñiguez, L., Martínez, M., Muñoz, J., Pallarés, S., \& Vázquez, F. (2002). Evaluación cualitativa del sistema de recogida de sangre en Cataluña. Revista Española de Salud Pública, 76, 437-450.

Jovelovitch, S. \& Bauer, M.W. (2002) Entrevista Narrativa. Em M. W. Bauer \& Gaskell. (Orgs), Pesquisa Qualitativa com Texto, Imagem e Som. Um manual prático (pp.90 - 113). Rio de Janeiro: Vozes.

Lama, G., Fernandez, J.R., \& Léon, P. (2002). Estudio epidemiológico de comportamientos de riesgo en adolescentes escolarizados de dos poblaciones, semirrural y urbana. Aten Primaria, 30(4), 214219.

Landini, F.P., Long, N.E., Leeuwis, C., \& Murtagh, S. (2014). Theorical Guideline for a Psychology of Rural Development. Cuadernos de Desarrollo Rural, 2(74), 125-147. 
Lei Federal $n^{\circ}$ 8069, de 13 de julho de 1990 (1990). Estatuto da Criança e do adolescente. Recuperado: 04/10/2015. Disponível: http://www.planalto.gov.br/ccivil/leis/L8069.htm

Lei Federal no 12852, de 05 de agosto de 2013. Estatuto da Juventude. Recuperado: 04/10/2015. Disponível: http://www.planalto.gov.br/ ccivil_03/_Ato2011-2014/2013/Lei/L12852.htm

Lopes de Oliveira, M.G. (2006). Identidade Narrativa e Desenvolvimento na Adolescência. Uma revisão crítica. Psicologia em Estudo, 11(2), 427-436.

Martins, A. (2010). A formação em psicologia e a percepção do meio rural: um debate necessário. Psicologia: ensino \& formação, 1(1), 83-98.

Martins, P. A., Trindade, Z.A., \& Almeida, E.M. (2003). O ter e o ser: representações sociais da adolescência entre adolescentes de inserção urbana e rural. Psicologia Reflexão e Critica, 16(3), 555568 .

Maurente, V. \& Tittoni, J.(2007). Imagens como estratégia metodológica em pesquisa: a fotocomposição e outros caminhos possíveis. Psicologia \& Sociedade, 19(3), 33-38.

Moura, D.H. (2013). Ensino médio integrado: subsunção aos interesses do capital ou travessia para a formação humana integral. Revista da Faculdade de Educação da USP, 39(3), 705720.

Neliubin, N.I. (2009). On the functional correspondence of meaning and senses in the structure of consciousness. Journal of Russian and East European Psychology, 47(5), 26-43.
Paulilo, M.I. (2004). Trabalho familiar: uma categoria esquecida de análise. Estudos Feministas, 12(1), 360.

Pratta, E.M.M. \& Santos, M.A. dos (2007). Família e adolescência: a influência do contexto familiar no desenvolvimento psicológico de seus membros. Psicologia em Estudo, 12(2), 247-256.

Rassial, J. (1997). A passagem adolescente: da família ao laço social. Porto Alegre: Artes e Ofícios.

Rassial, J. (1999). O adolescente e o psicanalista. Rio de Janeiro: Companhia de Freud.

Rodrigues,A. C\&Baptista, L.A. S. (2010). Cidades Imagem:Afirmações e enfrentamentos às políticas de Subjetividade. Psicologia \& Sociedade, 22(3), 422-429.

Sikora, D., Hidalgo, A., \& Junior, C. (2015). A Educação Rural no Paraná: uma análise a partir de Guarapuava (1930-1960). Educação \& Realidade, 40(4), 1127-1148.

Strauss, A. \& Corbin, J. (2008). Pesquisa Qualitativa: Técnicas e procedimentos para o desenvolvimento de teoria fundamentada. Porto Alegre: Artmed.

Stropasolas, V. (2004). O valor (do) casamento na agricultura familiar. Estudos Feministas, 12(1), 360.

Zago, N. (2016). Migração rural-urbana, juventude e ensino superior. Revista Brasileira de Educação, 21(64), 61-78.

\section{Sobre os autores}

Adolfo Pizzinato (adolfo.pizzinato@pucrs.br)

Doutor em Psicologia da Educação. Professor da Faculdade de Psicologia da Pontifícia Universidade Católica do Rio Grande do Sul (PUCRS). Programa de Pós-Graduação.

Milene Mabilde Petracco (milipetracco@hotmail.com)

Mestre em Educação. Doutora em Psicologia Social (PUCRS). Psicóloga do Instituto Federal de Educação IFSul.

Cristiano Hamann (cristiano.hamann@gmail.com)

Mestre em Psicologia Social (PUCRS). Doutorando em Psicologia Social e Institucional (UFRGS).

João Pedro Cé (joaopedroce@yahoo.br)

Mestre em Psicologia Social (PUCRS)

Eduarda Noal Rosa (eduardanrosa@hotmail.com)

Graduanda em Psicologia (PUCRS) 